\title{
IoT Based Secure Lock/Unlock System Using Google Assistant Based English And French Languages
}

\author{
https://doi.org/10.3991/ijoe.v17i10.24279 \\ Nagarjuna Telagam $\left.{ }^{1}{ }^{\bowtie}\right)$, U. Somanaidu ${ }^{2}$, M. Arun Kumar ${ }^{1}$, M. Sabarimuthu ${ }^{4}$ \\ Nehru Kandasamy ${ }^{5}$ \\ ${ }^{1}$ GITAM University, Bengaluru, India \\ ${ }^{2}$ Institute of Aeronautical Engineering, Hyderabad, India \\ ${ }^{4}$ Kongu Engineering College, Erode, India \\ ${ }^{5}$ National University of Singapore, Kent Ridge Singapore \\ nagarjuna473@gmail.com
}

\begin{abstract}
The user can utilise voice acknowledgement in making it more straightforward for individuals with inabilities to get to entryway frameworks and give better security to lives and properties. In this paper, the advancement of the technology is used for opening any locking system. We are implementing this type of module where it can be of low cost, and even physically disabled persons can open the door without any assistance. The Blynk app and a Wi-Fi module can access the system by giving the input and output as a voice recognition speech command. Hence, in this paper, any person can use google assistant from their smartphone to lock or unlock a secure system with just two controls, i.e., "Ok Google Lock Door one", "Ok Google Unlock Door one". This project works seamlessly for three locks in one system that can be operated separately using only one main microcontroller, i.e., Node-MCU ESP8266, and relays drivers so that our project can be quickly developed and deployed. The applications of this project are endless as technology constantly evolves. Suppose the user is connected to the internet and operated using Google Assistant. In that case, the lock is operated only from one account, making it secure and available to all who use smartphones and have a google account. Even for people who are blind, this can be an excellent way to lock and unlock their resources just with their voice. Anyone can utilise this project from their convenience, making it the easiest way for anyone to lock/unlock just by two words, i.e., "Ok, Google Lock Door."
\end{abstract}

Keywords-Locks, Node-MCU ESP8266, Relay drivers, Google assistant, Security, Voice

\section{Introduction}

A Door-Automation system based on a speech command pin is a good way of locking or unlocking the door using a voice module that recognises the voice. If the voice matches, then the further step of identifying the command is initiated. Otherwise, we get a prompt of invalid command on our smartphone.[1] This article uses a website URL-based system to monitor input. They use the voice command of the Raspberry pi 
board Wireless communication and $\mathrm{v} 3$ module for voice recognition that cannot be recorded The sound made before. They have used electromagnetic locks to close the system door, Open and close it.[2] A system that acts as a voice modification wireless device improves the active system that performs digital activation. Speech recogniser has a modern fee Technology, and have undergone different numbers of noise tests, such as digital and few characters. The above article will put forward some additional ideas on security intelligent smart doors Lock systems and use the digital lock to implement via Bluetooth, apps and wireless. However, they did not discuss an idea where the user can use commands and door automation with the help of voice recognition systems.[3] In this article, the author proposes an approach composed of digital locks for an ordinary door. People used to have mechanical locks to open the door, but as children and older people, it is hard for disabled people to always carry it with them, so the digital lock is used together with the password. Sometimes the PIN may be forgotten, so only use an electronic lock with a digital lock, and a spare battery is used. If there is electricity, use an electric lock. If there is no electricity when using a smart card, RFID can easily use numbers to open the door lock.[4]

This article is trained to make it more flexible in an adaptable environment with fewer requirements for modifying tracking records, adding a single voice recognition for more demographic data, and adapting to any environment in the current climate change scenario. Here, they use a microcontroller, a single voice module and a Bluetooth module to get the required output, and the range they get in this target is 10-20 meters, and the required time is 140 milliseconds. [5] In this article, the system is used for the entire process of a smartphone application. They use different sensors to operate the electric door, lock the door using a magnetic sensor, and use a dust sensor to detect air pollution. They are implemented through OTP, where any interference occurs in less than 10 seconds, the door is locked, and the message is transmitted to the registered ID. The camera is activated, and corresponding images and videos are recorded from CCTV [6]. In this system, they use the same Arduino microcontroller and Arduino smartphone to turn on and off access to it using a wireless device called Bluetooth to transmit data or obtain the output required for data. They use the power supply as Batteries and relays have been used to control the current, they have used solenoids for output, and the system has been used to obtain the code to be executed, and by using the COM port, the system may be hacked, and access may be wrong.[7] In this article, they implemented the system by using a Wi-Fi module and a GSM module. They implemented a microcontroller by using two types of wired and wireless equipment, and in this system, two DC motor is used to open the door and keep it open. Since the system's operating time is turned off when the program is implemented, all family members can use the modified system described in this article.[8] In this system, innovative smart technology automatically opens closed doors through smartphones and GSM modems. They use components to implement the system through servers, web services, and IP cameras and propose Wi-Fi access for connection. The different parts to be operated, connect the device wirelessly, and obtain a strict security level are implemented widely. The system successfully uses GSM because when the Wi-Fi range is exceeded, GSM can work typically.[9] In this article, the system executes the required components, such as microcontrollers, Bluetooth modules, fire and temperature 
sensors, to detect emergencies of fire or theft in intelligent houses, and some tests are performed to modify the sensing. The object can be tracked perfectly and is only 10 meters away from the Bluetooth device.[10],[11],[12],[13].

\section{The Proposed system model}

This article Proposes a system of locks that can be operated just by our smartphone using google assistant. The user can utilise this system from anywhere globally with the user connected with the internet and operated using Google Assistant. The lock is operated only from one account, making it secure and available to all who use smartphones and have a google account. Even for people who are blind, this can be a fantastic way to lock and unlock their resources just with their voice. Anyone can utilise this locking system from their convenience, making it the easiest way for anyone to lock/unlock just by two words, i.e., "Ok, Google Lock Door". This model will allow us to reach out to most people as most people are using smartphones. The previous models have additional components like Bluetooth module, voice module mic, camera, fingerprint scanner, etc. For the proper working of that system, the user would have to be present at the lock spot only.

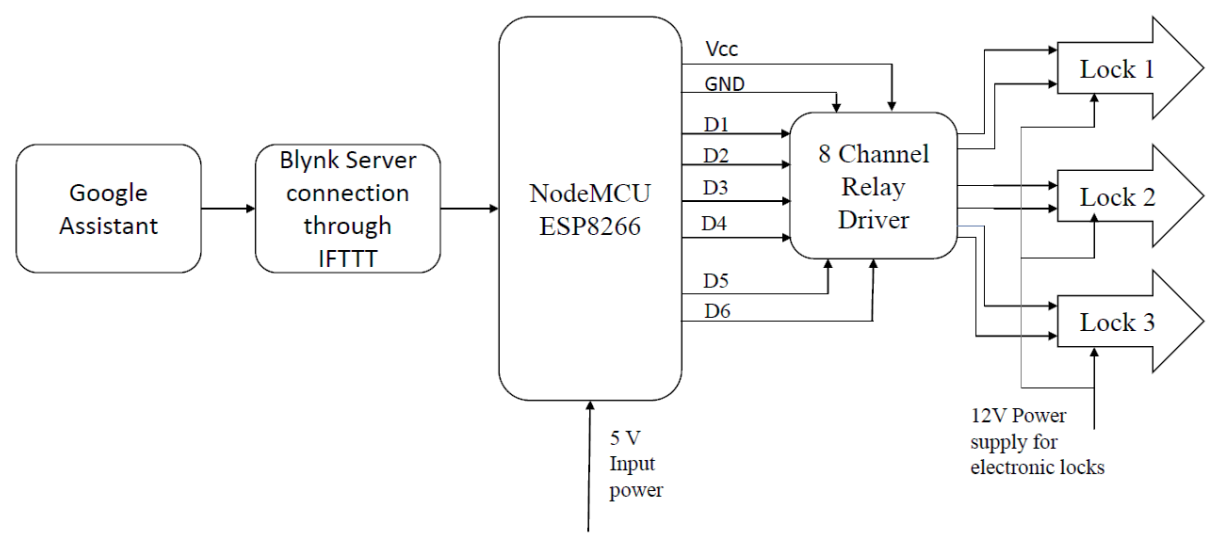

Fig. 1. Block diagram of the proposed system

The existing system depends on Bluetooth, which has a short-range connection, i.e., 100 meters, and we would have to give inputs for the working for this system. Moreover, in the case of voice module systems, a person/user must be present in the same place as the lock, and the same is the case with other biometric modules systems. Figure 1 shows the block diagram with google assistant. However, with this proposed system, the user will solve these two situations since the user is not using any additional components except the lock, the microcontroller and the relays [14]. 


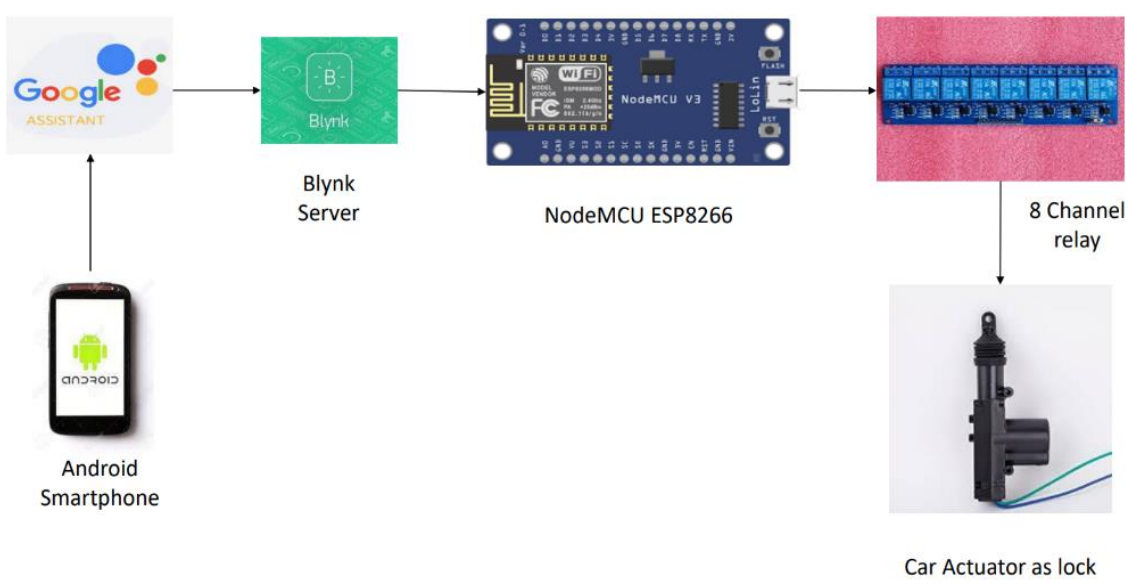

Fig. 2. Proposed system layout

With the help of google assistant, the user can operate the locking system from any distance. The user requires the BLYNK app and IFTTT to connect the locks to the google assistant account. For this paper, we are using three different locks that will operate independently. Since IFTTT supports a set of languages, we implement this system with two languages, i.e., English and French. This system does not compromise the working and speed of operation, making this suitable for many purposes.

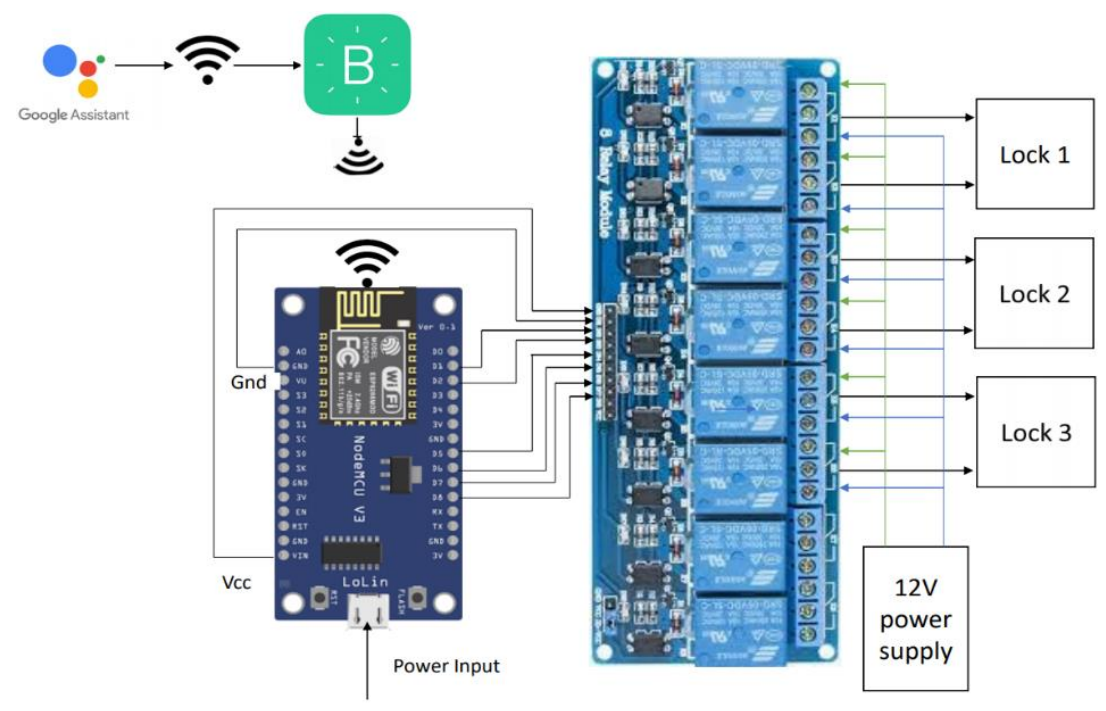

Fig. 3. Circuit diagram of the proposed locking/unlocking system

This project uses a NodeMCU ESP8266, 8-channel Relay, Car actuators (3), battery (12V-7.2AH). We created a new Blynk app project and added switches to 3 locks for 
locking and unlocking. Written code in Arduino IDE and dumped code into NodeMCU. In this project, the user has used a hidden network for Wi-Fi connection, Add network and type network name and password used in code. The new project is created in the Blynk app, and two different buttons are made with NodeMCU configuration, one for lock and one for unlocking. The user will get a Unique auth-code related to the project to his google registered mail, and this auth-code is used to control and connect the locks to the NodeMCU. The user has to login in IFTTT server with his google account to use the google assistant feature. Also, the user creates a new applet with google assistant to enter the commands to operate the locking system.

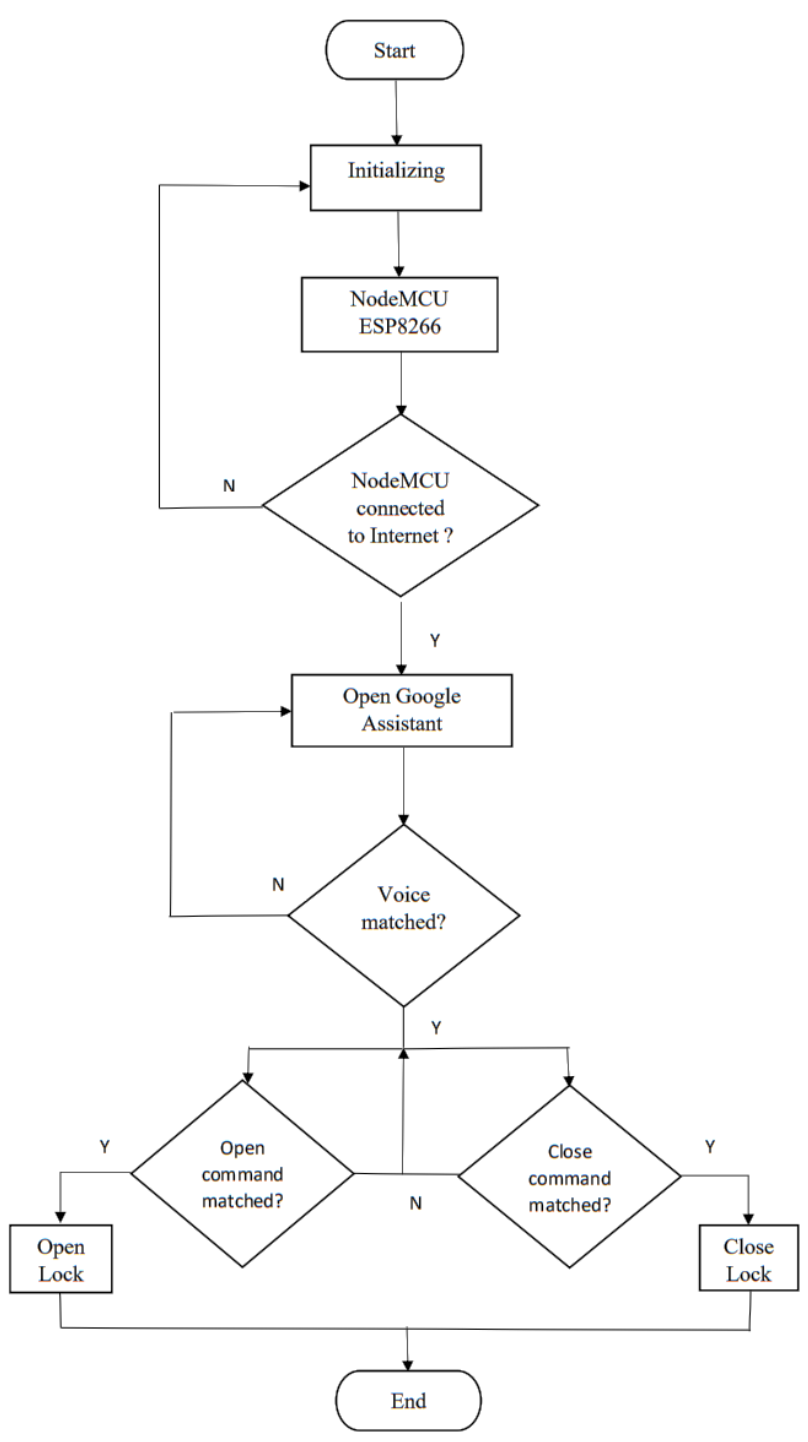

Fig. 4. Flow chart of the proposed system 


\section{Algorithm}

STEP 1: Start and initialise NodeMCU ESP8266.

STEP 2: Dump the code into NodeMCU from Arduino IDE.

STEP 3: Check whether the NodeMCU is connected to the internet if not initialise again.

STEP 4: Launch Google assistant if voice matches.

STEP 5: Give Commands to google assistant.

STEP 6: If the command matches, then lock is operated; else, no response.

STEP 7: End and wait for Step 4.

Table 1. List of English and French commands used in this project

\begin{tabular}{|l|c|c|c|}
\hline \multicolumn{1}{|c|}{$\begin{array}{c}\text { Command } \\
\text { (English) }\end{array}$} & $\begin{array}{c}\text { Response } \\
\text { (English) }\end{array}$ & $\begin{array}{c}\text { Command } \\
\text { (French) }\end{array}$ & $\begin{array}{c}\text { Response } \\
\text { (French) }\end{array}$ \\
\hline Lock one & Locking one & Verrouiller un & Verrouiller un \\
\hline Unlock one & Unlocking one & Débloquez-en un & Déverrouiller un \\
\hline Lock two & Locking two & Verrouiller deux & Verrouiller deux \\
\hline Unlock two & Unlocking two & Débloquez deux & Déverrouiller deux \\
\hline
\end{tabular}

\section{Circuit Diagram, BLYNK app and IFTTT Operation}

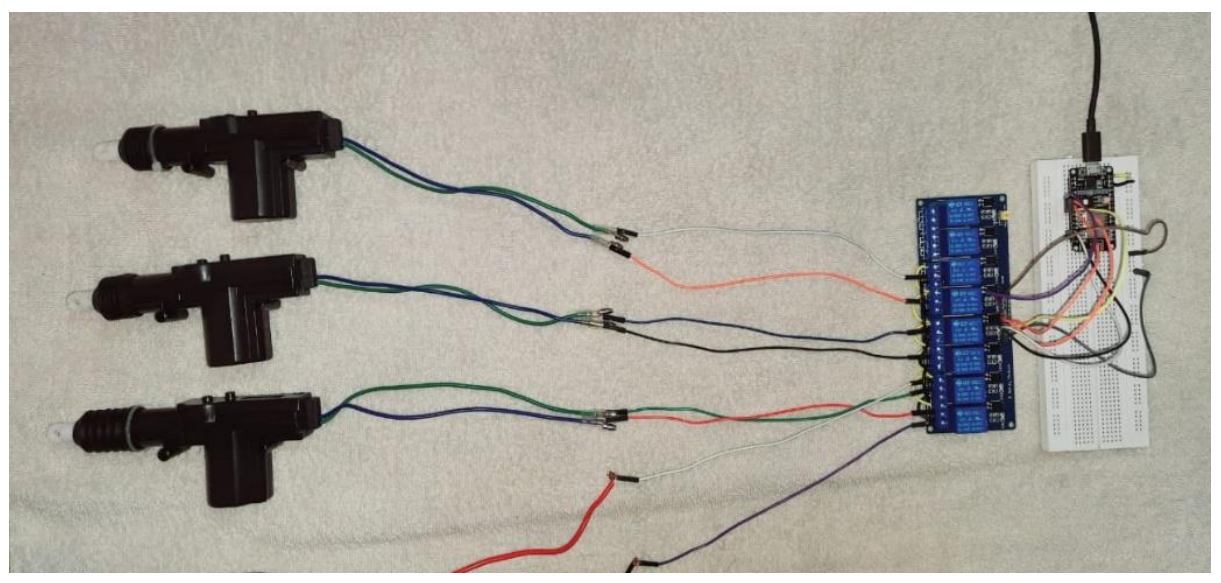

Fig. 5. Circuit diagram with breadboard connections

We have assembled the circuit in the following way such that three locks (actuators) will work depending on the input the user gives. The circuit is controlled by a microcontroller and is dependent on relays [15]. 


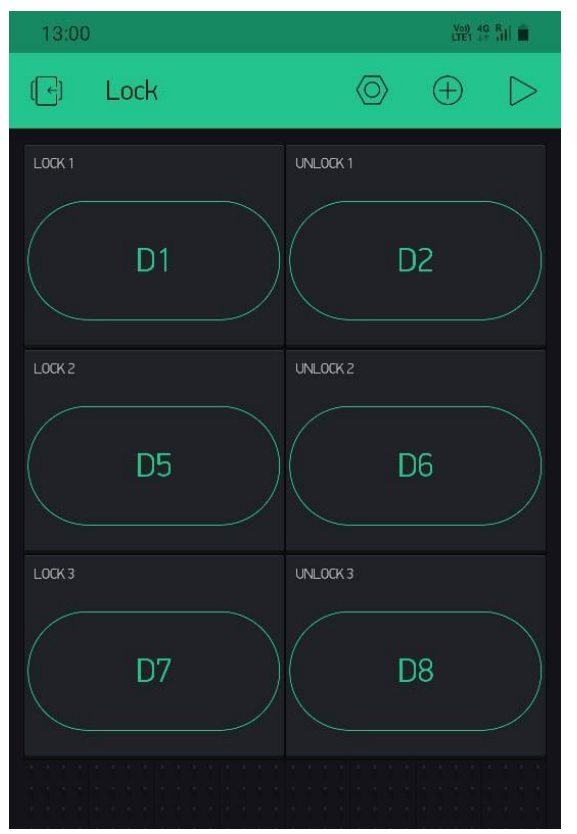

Fig. 6. Buttons in Blynk App in Project LOCK

This fig 7 shows the lock buttons settings in the Blynk app, it is 1 and 0 because the user has to use active low relays, and a push switch is used so that as soon as the lock is done, the relay can come to its neutral state.

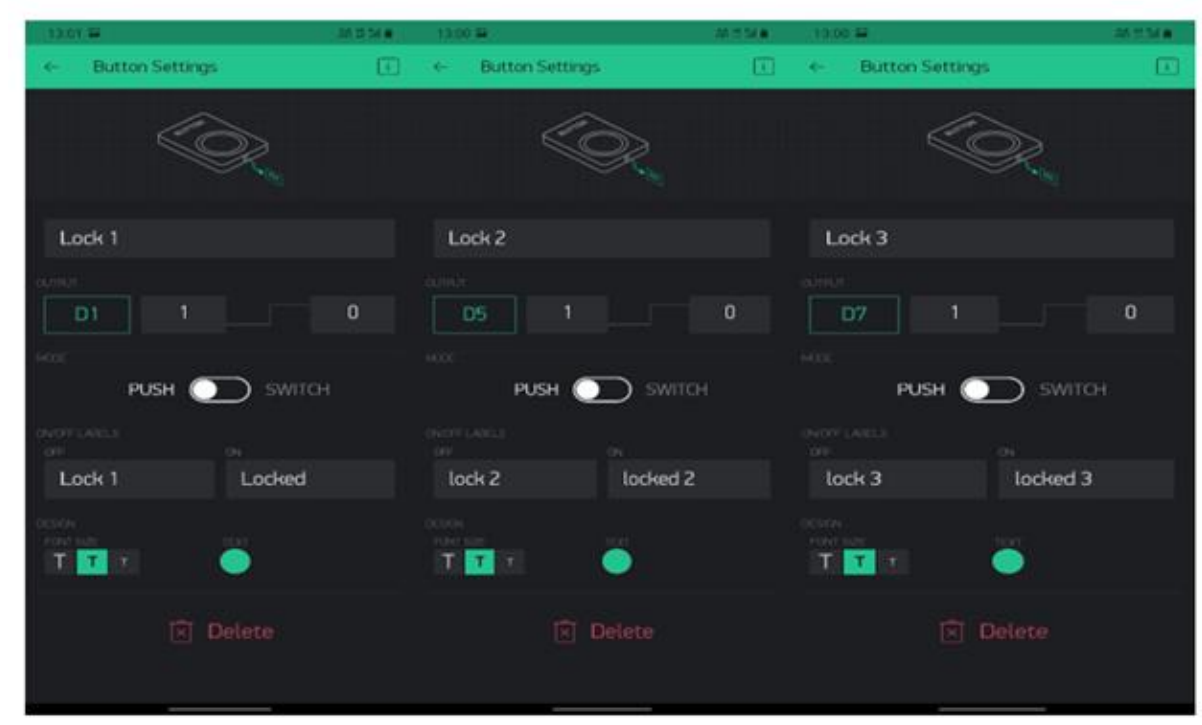

Fig. 7. Lock Button settings. 
Paper-IoT Based Secure Lock/Unlock System Using Google Assistant Based English And French...

Figure 8 shows the unlock buttons settings in the Blynk app, and it is 1 and 0 because the user has to use active low relays, and a push switch is used so that the relay is done as soon as unlocking is done can come to its neutral state.

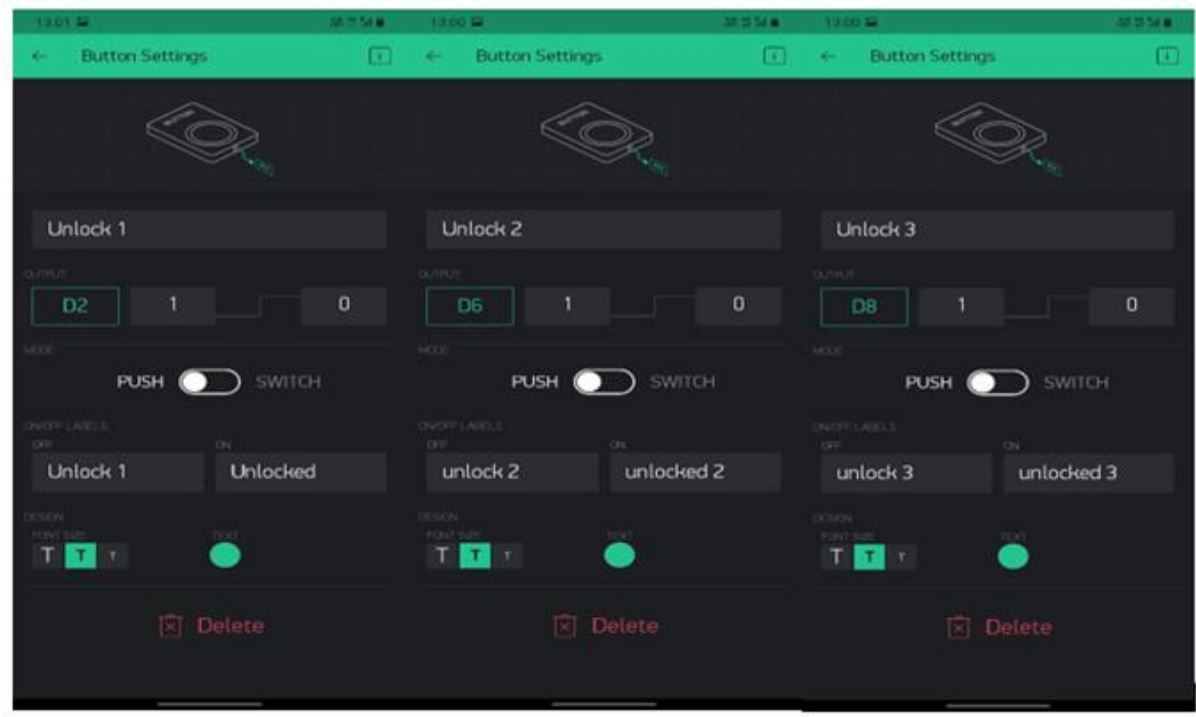

Fig. 8. Unlock button settings.

If $\varphi_{i}$ say a simplophraso

\section{$\bullet$}

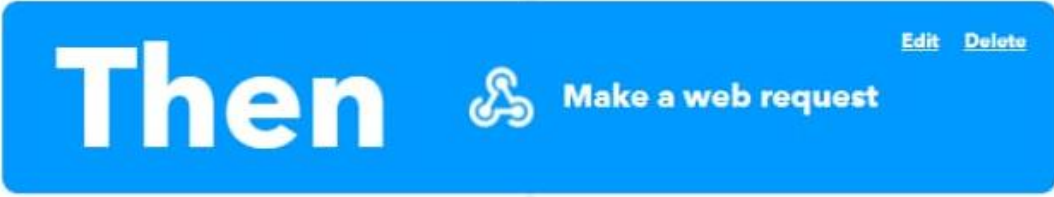

\section{And \& Make a web request Elith Delote}

$\boldsymbol{\oplus}$

Fig. 9. IFTTT Applet Creation. 
IFTTT (If this, then that) is an open-source platform for linking two things to make use of them efficiently and smartly, and this will allow us to connect the google assistant to blynk app project buttons.

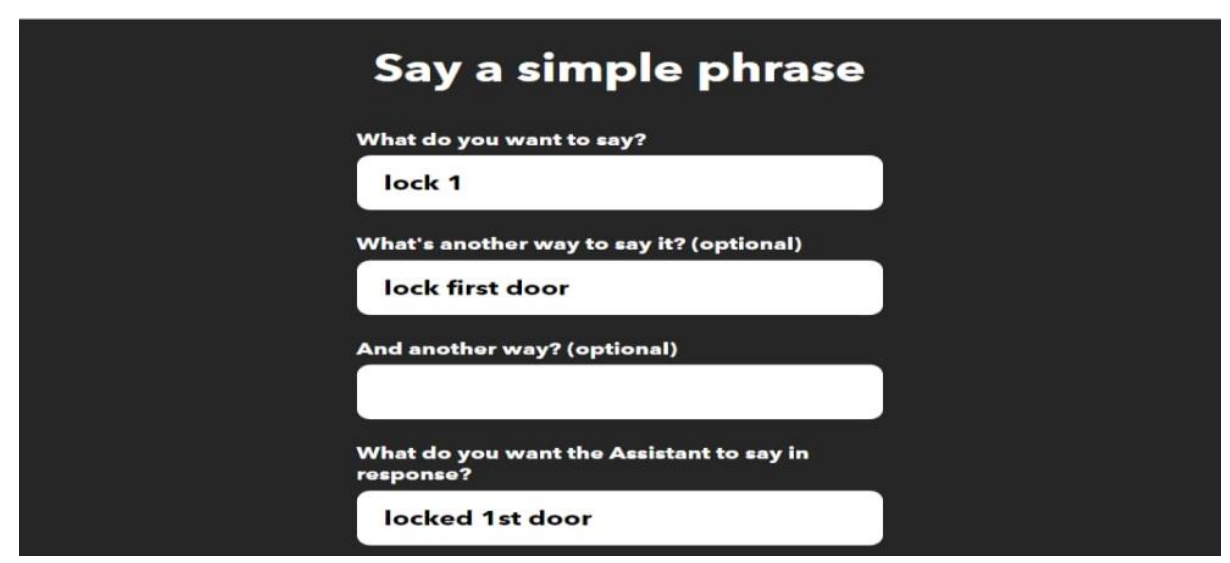

Fig. 10.Google assistant link operation in Applet (IFTTT).

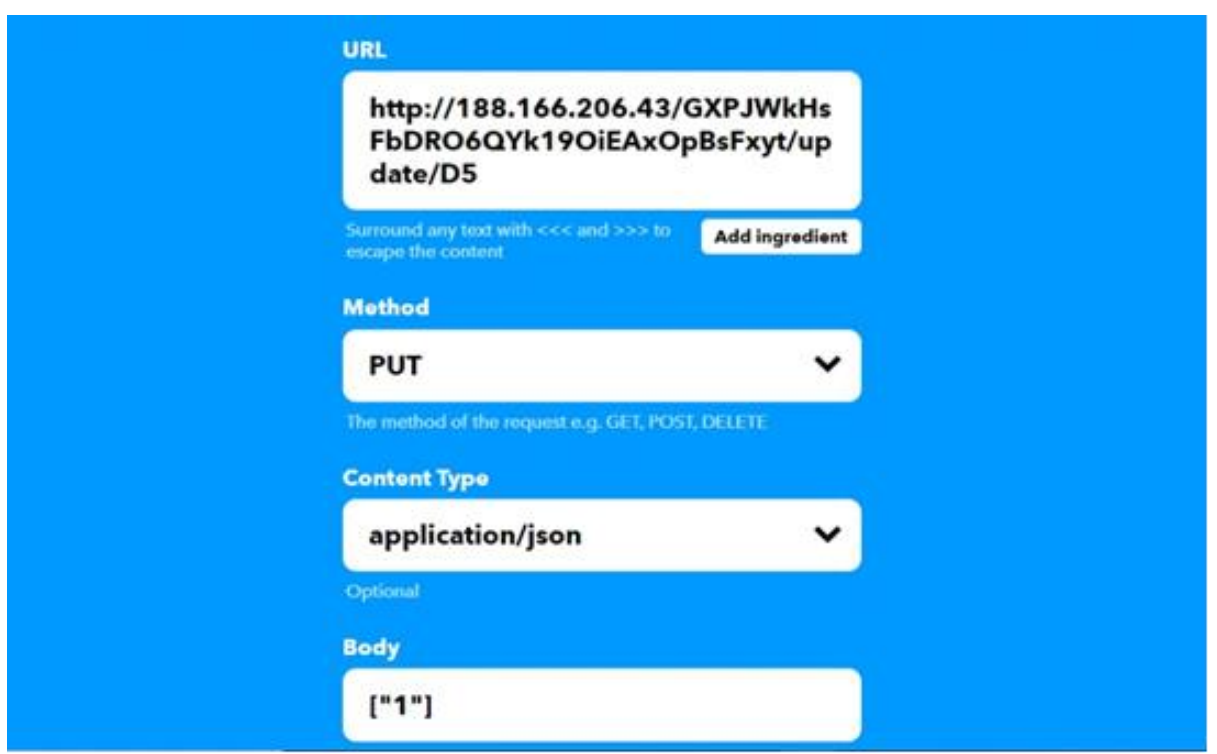

Fig. 11.Webhooks link connection in Applet (IFTTT).

In IFTTT, for creating webhooks link,s the user need to add some server addresses

- For getting the blynk server IP address, the user has to open the command prompt in our desktop and type "ping blynk-cloud.com" and press enter.

- After that, the user should get (ping statistics for "IP address") the IP address. 
In IFTTT, while creating webhook link the user has to enter URL:

- http://(IP address of Blynk server)/(Authtoken)/update/(GPIO pin)

- Here IP address the user can find via command prompt.

- The Authtoken is from the Blynk app.

- The GPIO pin is the combination of raw PIN and port, i.e. if the user has to operate D1 port, the user has to use the first letter of port, and the last number of the raw PIN of that port, example:- for D1 port Raw PIN is GPIO5 hence the GPIO pin to be entered in URL has to be D5.

- Method has to be PUT.

- Content type is application/json.

- Body should be ["1"] for turning on the port and ["0"] for turning off the port since the user is using the active low relay

\section{$4 \quad$ Results and Discussions}

Table 2. System devices and their specifications

\begin{tabular}{|l|l|}
\hline \multicolumn{1}{|c|}{ Devices } & \multicolumn{1}{c|}{ Value/Id } \\
\hline Node-MCU & ESP8266 \\
\hline 8 Channel Relays & Relay Active Low \\
\hline Locks & L1, L2, L3 \\
\hline Battery & $12 \mathrm{~V}$ \\
\hline DC Adapter & $5 \mathrm{~V}$ \\
\hline
\end{tabular}

In this figure 12, lock, one is expanded, indicating the actuator is lockedSince the "Lock 1" command is given to google assistant, the user can see that lock 1 is extended/locked.

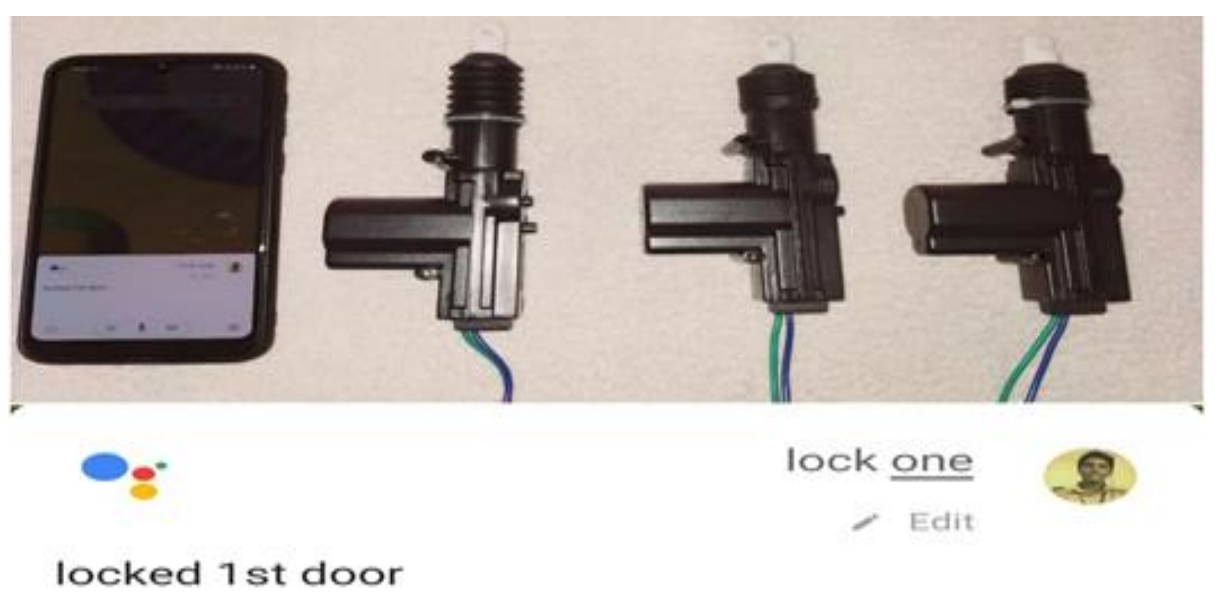

Fig. 12.English language command to lock $1^{\text {st }}$ door 
In this figure 13, lock one is again contracted to indicate the actuator is locked. Since the "Unlock 1" command is given to google assistant, the user can see that lock 1 is contracted/unlocked.

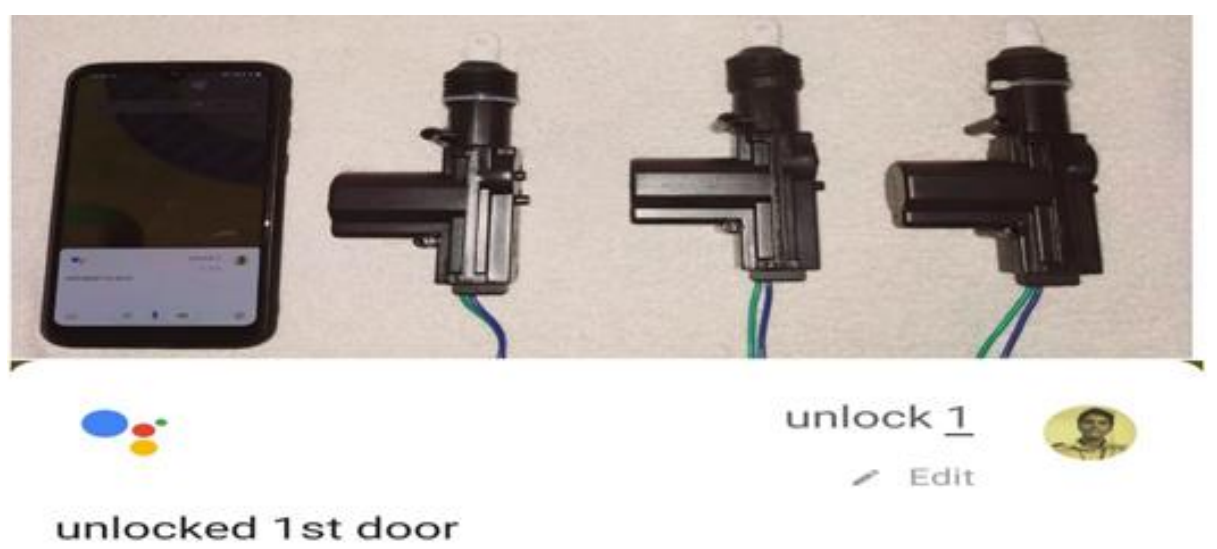

Fig. 13.English language command to unlock $1^{\text {st }}$ door.

In this figure 14, lock two is expanded, indicating the actuator is locked Since the "Serrure 2" command is given (in French) to google assistant, the user can see that lock 2 is expanded/locked.

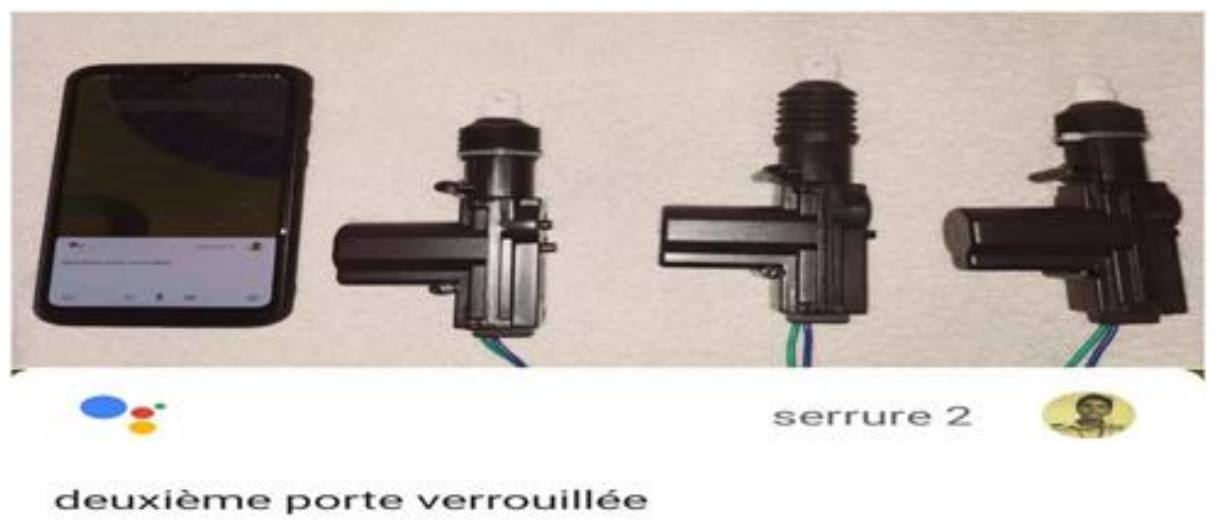

Fig. 14.French language command to lock $2^{\text {nd }}$ door

In this figure 15 , lock two is contracted, indicating the actuator is locked. Since the "Déverrouiller 2" command is given (in French) to google assistant, the user can see that lock 2 is contracted/unlocked. 


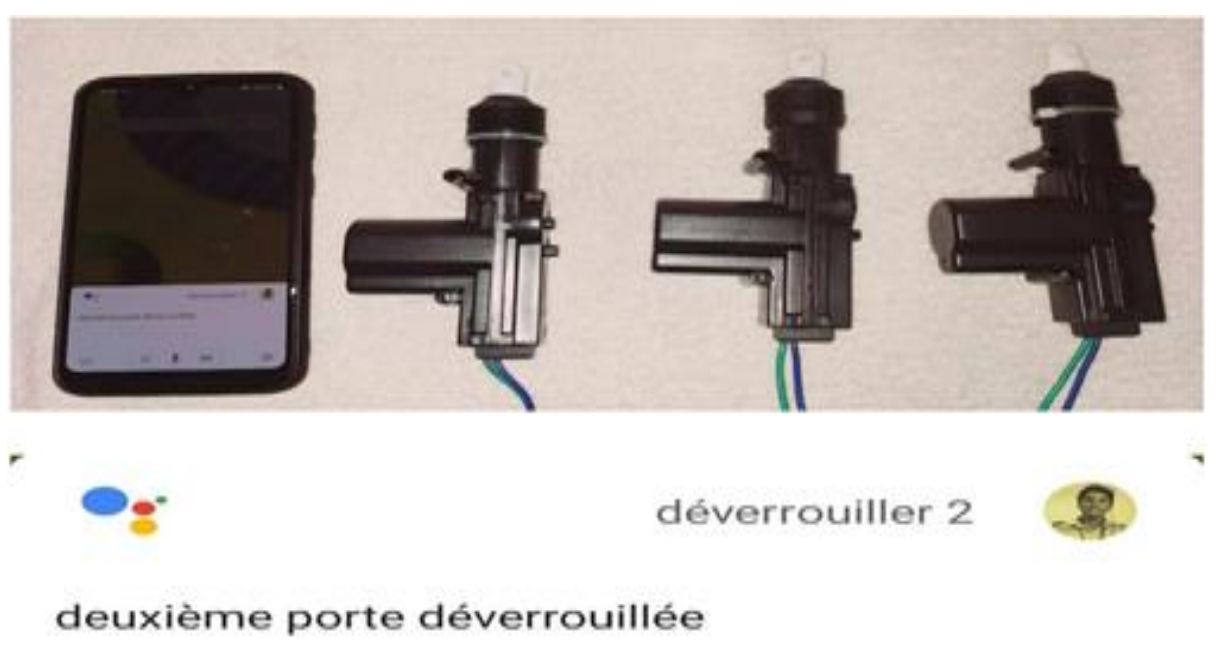

Fig. 15.French language command to unlock $2^{\text {nd }}$ door

Table 3. No of experiments for correct pronunciation

\begin{tabular}{|l|c|c|c|}
\hline No of Experiments & Correct Voice & Correct pronunciation & Working \\
\hline 1 & Yes & Yes & Yes \\
\hline 2 & Yes & Yes & Yes \\
\hline 3 & Yes & Yes & Yes \\
\hline 4 & No & No & No \\
\hline 5 & Yes & No & No \\
\hline
\end{tabular}

Table 4. English and French language commands and their responses

\begin{tabular}{|l|l|}
\hline \multicolumn{1}{|c|}{ COMMAND } & \multicolumn{1}{c|}{ RESPONSE } \\
\hline Lock 1 & Lock number 1 is expanded, indicating that it is locked. \\
\hline Unlock 1 & Lock number 1 is contracted, indicating that it is unlocked. \\
\hline Lock 2 & Lock number 2 is expanded, indicating that it is locked. \\
\hline Unlock 2 & Lock number 2 is contracted, indicating that it is unlocked. \\
\hline Lock 3 & Lock number 3 is expanded, indicating that it is locked. \\
\hline Unlock 3 & Lock number 3 is contracted, indicating that it is unlocked. \\
\hline Serrure 2 (Lock in French) & Lock number 2 is expanded, indicating that it is locked. \\
\hline Déverrouiller2 (Unlock in French) & Lock number 2 is contracted, indicating that it is unlocked. \\
\hline
\end{tabular}

\section{Conclusion}

This project intends to operate the three locks from google assistant without any limitations or drawbacks and be affordable and secure. After creating this lock system, the user can say that the design and locks work as the user imagined without any noticeable delay. We have used very few components in this project which has helped us to reduce the cost significantly. Now that our project works as intended, we can say that 
these lock systems have way more applications in the future and can be modified to our likings as we can create a whole door system by adding extra motors apart from the locks. The security of this project solely depends on the user as he is himself the key to the locks. This project eliminates the drawbacks of existing locks, i.e. users cannot operate locks when present near it, and relays used in every electronic lock system are a delicate part that we have solved by giving power to the relay just for that fraction of time have to operate the motor. Since these locks are operated with the open-sourced google assistant, we can operate them with any smartphone. We can be used in multiple languages as IFTTT will update many more languages to its server. We hope that many more implications of these projects will be done in future by adding more components that will enhance usability and security.

\section{$6 \quad$ References}

[1] Ajay V, K B Reddy, P Shiva Teja, S Naga Akash, Dr Bharathi SH, "Door-Automation Syatem Based on Speech Command Pin Using Android Smartphone" published in International journal of Advanced Science and Technology in 2020.

[2] Yuan-Chin Yu, "A practical Digital Door Lock for Smart Home" published in IEEE International Conference Consumer Electronics in 2018.

[3] Xiohua Zeng, Abraham, Abraham O. Fapoujuwo, RobertmJ. Davies, "Design and performance Evaluation of Voice Activated Wireless Home Devices", IEEE Transactions on Consumer Electronics.

[4] De Vries, N. Cross, and D. P. Grant, Design Methodology and Relationships with Science: Introduction. Eindhoven: Kluwer Academic Publishers. p. 32. 1992, Archived from the original on 2016-10-24

[5] Hem Kamdar, Roshan Karkera, Archit Khanna, Pranav Kulkarni, Supriya Agrawal (Student) - B. Tech Computer Science, NMIMS University, Maharashtra, India.

[6] M. Cho, and J. Kang, - Voice Security on the Rise: Examining the Path to Secure Voice Automation, Alticast Inc. Colorado, 2017.

[7] Alkar, A. Z., \& Buhur, U. (2005). An Internet-Based Wireless Home Automation System for Multifunctional Devices. IEEE Consumer Electronics. https://doi.org/10.1109/tce. $\underline{2005.1561840}$

[8] Piyare, R. and Tazil, M. (2011) Bluetooth Based Home Automation System Using Cell Phone. IEEE 15th International Symposium on Consumer Electronics (ISCE), Singapore. https://doi.org/10.1109/isce.2011.5973811

[9] S. A. Celtek, M. Durgun, and H. Soy, "Internet of Things based smart home system design through wireless sensor/actuator networks," in 2017 2nd International Conference on Advanced Information and Communication Technologies (AICT), 2017, pp. 15- 18. https://doi. org/10.1109/aiact.2017.8020054

[10] D. Wang, "The Internet of Things the Design and Implementation of Smart Home Control System," in 2016 International Conference on Robots \& Intelligent System (ICRIS), 2016, pp. 449-452. https://doi.org/10.1109/icris.2016.95

[11] Telagam, N., Kandasamy, N., Nanjundan, M., \& Arulanandth, T. S. (2017). Smart Sensor Network-based Industrial Parameters Monitoring in IOT Environment using Virtual Instrumentation Server. Int. J. Online Eng., 13(11), 111-119. https://doi.org/10.3991/ijoe.v13i11.7630

[12] Somanaidu, U., Nagarjuna Telagam, K. Nehru, and N. Menakadevi. "USRP 2901 based FM transceiver with large file capabilities in a virtual and remote laboratory." iJOE 14, no. 10 (2018). https://doi.org/10.3991/ijoe.v14i10.8283 
[13] Nagarjuna, T., Lakshmi, S., \& Nehru, K. (2019). USRP 2901-based SISO-GFDM transceiver design experiment in a virtual and remote laboratory. The International Journal of Electrical Engineering \& Education, 0020720919857620. https://doi.org/10.1177/0020720 $\underline{919857620}$

[14] Kandasamy, N., Telagam, N., Seshagiri Rao V. R, \& Arulananth, T. S. (2017). Simulation of Analog Modulation and Demodulation Techniques in Virtual Instrumentation and Remote Lab. Int. J. Online Eng., 13(10), 140-147. https://doi.org/10.3991/ijoe.v13i10.7575

[15] Telagam, N., Nanjundan, M., Kandasamy, N., \& Naidu, S. (2017). Cruise Control of Phase Irrigation Motor Using SparkFun Sensor. Int. J. Online Eng., 13(8), 192-198. https://doi.org /10.3991/ijoe.v13i08.7318

\section{Authors}

Nagarjuna Telagam is with the Electronics and Communication Engineering Department, GITAM University, Bangalore, India and Currently Research Scholar in 5GGFDM, and interested in Virtual Instrumentation. He is Anna University rank holder (20) for Masters in Engineering Degree in the year 2013 in State Level Award. He published more than 40 papers in different Scopus Indexed Journals and SCIE Journals and has published seven book chapters in international publishers.

U. Somanaidu received B.TECH. In Electronics and Communications Engineering from JNTU University, Kakinada, in 2011, Completed M. Tech. in PEC Engineering college, from JNTUK University, Kakinada. His research interests include VLSI and Embedded systems (Email: somanaidu.409@gmail.com).

Dr M Arun Kumar is working as an Assistant professor in the Department of EECE at GITAM, Bengaluru Campus, Bengaluru, India. He completed his Bachelor's degree in Electronics \& Communication Engineering from Anna University, Chennai, India, in 2010. He acquired his Masters in VLSI Design from Kongu Engineering College, Anna University, India, in 2012. He completed his PhD degree from Anna University (Email: manokavi2011@gmail.com).

Mr M. Sabarimuthu is working as an Assistant Professor in the Electrical and Electronics Engineering Department at Kongu Engineering College, Perundurai, India. He is currently pursuing his research under the supervision of Professor N. Senthilnathan from the same institution (Email: eeesabari@gmail.com@gmail.com).

Nehru Kandasamy is a research fellow at the National University of Singapore and received his Bachelor Degree in Erode Sengunthar Engineering College, Anna University, in 2005. Moreover, he obtained his Master Degree in R.M.K Engineering, Anna University, in 2007. Furthermore, he also obtained outstanding master student that year. $\mathrm{He}$ is obtained his $\mathrm{PhD}$ in 2014 at the Faculty of Information and Communication Engineering, Anna University, India. His main research interest is Low Power VLSI, Testing of VLSI Circuits, FPGA Design, CAD for VLSI, Signal processing. He has published papers on these topics in various international journals (Email: nnehruk@gmail.com).

Article submitted 2021-05-26. Resubmitted 2021-07-03. Final acceptance 2021-07-07. Final version published as submitted by the authors. 